\title{
Warm winter, thin ice?
}

\author{
Julienne C. Stroeve ${ }^{1,2}$, David Schroder ${ }^{3}$, Michel Tsamados ${ }^{1}$, and Daniel Feltham ${ }^{3}$ \\ ${ }^{1}$ Centre for Polar Observation and Modelling, Earth Sciences, University College London, London, UK \\ ${ }^{2}$ National Snow and Ice Data Center, University of Colorado, Boulder, CO, USA \\ ${ }^{3}$ Centre for Polar Observation and Modelling, Department of Meteorology, University of Reading, Reading, UK
}

Correspondence: Julienne C. Stroeve (j.stroeve@ucl.ac.uk)

Received: 29 December 2017 - Discussion started: 11 January 2018

Revised: 9 April 2018 - Accepted: 10 April 2018 - Published: 30 May 2018

\begin{abstract}
Winter 2016/2017 saw record warmth over the Arctic Ocean, leading to the least amount of freezing degree days north of $70^{\circ} \mathrm{N}$ since at least 1979. The impact of this warmth was evaluated using model simulations from the Los Alamos sea ice model (CICE) and CryoSat-2 thickness estimates from three different data providers. While CICE simulations show a broad region of anomalously thin ice in April 2017 relative to the 2011-2017 mean, analysis of three CryoSat-2 products show more limited regions with thin ice and do not always agree with each other, both in magnitude and direction of thickness anomalies. CICE is further used to diagnose feedback processes driving the observed anomalies, showing $11-13 \mathrm{~cm}$ reduced thermodynamic ice growth over the Arctic domain used in this study compared to the 20112017 mean, and dynamical contributions of +1 to $+4 \mathrm{~cm}$. Finally, CICE model simulations from 1985 to 2017 indicate the negative feedback relationship between ice growth and winter air temperatures may be starting to weaken, showing decreased winter ice growth since 2012, as winter air temperatures have increased and the freeze-up has been further delayed.
\end{abstract}

\section{Introduction}

It is well known that Arctic air temperatures are rising faster than the global average (e.g., Bekryaev et al., 2010; Serreze and Barry, 2011). The thinning and shrinking of the summer sea ice cover have played a role in this amplified warming, which is most prominent during the autumn and winter months, as the heat gained by the ocean mixed layer during ice-free summer periods is released back to the atmosphere during ice formation (e.g. Serreze et al., 2009; Screen and
Simmonds, 2010). However, Arctic amplification has been found in climate models without changes in the sea ice cover (Pithan and Mauritsen, 2014). Increased latent energy transport (Graversen and Burtu, 2016), the lapse rate feedback (Pithan and Mauritsen, 2014; Graversen, 2006) and changes in ocean circulation (Polyakov et al., 2005) have also contributed. Furthermore, cyclones are effective means of bringing warm and moist air into the Arctic during winter (e.g., Boisvert et al., 2016).

Winter 2015/2016 was previously reported as the warmest Arctic winter recorded since records began in 1950 (Cullather et al., 2016). Warming was Arctic-wide, with temperature anomalies reaching $+5^{\circ} \mathrm{C}$ (Overland and Wang, 2016) and temperatures near the North Pole hitting $0{ }^{\circ} \mathrm{C}$ (Boisvert et al., 2016). Part of the unusual warming was linked to a strong cyclone that entered the Arctic in December 2015 (Boisvert et al., 2016), resulting in reduced thermodynamic ice growth and thinning within the Kara and Barents seas (Ricker et al., 2017a; Boisvert et al., 2016). This was one of several cyclones to enter the Arctic that winter as a result of a split tropospheric vortex that brought warm and moist air from the Atlantic Ocean towards the pole (Overland and Wang, 2016). Winter 2016/2017 once again saw temperatures near the North Pole reach $0{ }^{\circ} \mathrm{C}$ in December 2016 and February 2017 (Graham et al., 2017). These warming events were similarly associated with large storms entering the Arctic (Cohen et al., 2017). It has been suggested that the recent warm winters represent a trend towards increased duration and intensity of winter warming events within the central Arctic (Graham et al., 2017).

In general, warm winters, combined with increased ocean mixed layer temperatures from summer sea ice loss, delay freeze-up, impacting the length of the ice growth season and 
the period for snow accumulation on the sea ice. Stroeve et al. (2014) previously evaluated changes in the melt onset and freeze-up, showing large delays in freeze-up within the Chukchi, East Siberian, Laptev and Barents seas, with delays increasing in the order of +10 days per decade. Later freeze-up has a non-trivial influence on basin-wide sea ice thickness: ice grows thermodynamically faster for thin ice than for thick ice (Bitz and Roe, 2004). More subtle effects involving the timing of ice growth relative to major snow precipitation events in fall have been shown to also control the growth rate of sea ice thickness; ice grows faster for a thinner snow pack (Merkouriadi et al., 2017). Nevertheless, the maximum winter sea ice extent in 2017 set a new record low for the 3 rd year in a row. Have the recent warm winters played a role in these record low winter maxima by reducing winter ice formation?

Ricker et al. (2017a) previously evaluated the impact of the 2015/2016 warm winter on ice growth using sea ice thickness derived from blending CryoSat-2 (CS2) radar altimetry with those from Soil Moisture and Ocean Salinity (SMOS) radiometry (Ricker et al., 2017b). They found anomalous freezing degree days (FDDs) between November 2015 and March 2016 within the Barents Sea of $1000^{\circ}$ days coincided with a thinning of approximately $10 \mathrm{~cm}$ in March compared to the 6-year mean. While near-surface air temperatures largely control thermodynamic ice growth, other processes also impact ice growth, including ocean circulation, sensible and latent heat exchanges. Furthermore, winter ice thickness is not only a result of thermodynamic ice growth, but rather the combined effects of thermodynamic and dynamic processes. A thinner ice cover is more prone to ridging and rafting, as well as ice divergence, leading to new ice formation within leads and cracks within the ice pack. However, this was not evaluated by Ricker et al. (2017a).

In this study we evaluate the impact of the 2016/2017 anomalously warm winter on Arctic sea ice thickness using the Los Alamos sea ice model (CICE) (Hunke et al., 2015) and satellite-derived CS2 thickness data from three different sources: Centre for Polar Observation and Modeling (CPOM) (Tilling et al., 2017), Alfred Wegener Institute (AWI) (Hendricks et al., 2016) and NASA (Kurtz and Harbeck, 2017). CICE is initialized with CPOM CS2 subgrid scale ice thickness distribution (ITD) fields in November and run forward with NCEP Reanalysis-2 (NCEP2) atmospheric reanalysis data (Kanamitsu et al., 2002, updated 2017). The model run is subsequently compared over the winter growth season to CS2 thickness from the three different data providers and contributions of thermodynamics vs. dynamics to the thickness anomalies are evaluated. While the focus is on the 2016/2017 ice growth season, a secondary aim is to compare existing CS2 products to inform the community on uncertainties in these estimates and inform on model limitations. Thus, results are also presented for other years during the CS2 time-period for comparison. To our knowl- edge, this is the first study to compare different CS2 data products over the lifetime of the mission.

\section{Methods}

\subsection{Ice thickness distribution (ITD) from Cryosat-2}

The CryoSat-2 radar altimetry mission was launched April 2010, providing estimates of ice thickness during the ice growth season. CS2 provides freeboard estimates, or the height of the ice surface above the local sea surface, which when combined with information on snow depth, snow density and ice density can be converted to ice thickness assuming hydrostatic equilibrium (e.g., Laxon et al., 2013). Here we evaluate ice thickness fields provided by three different data providers in order to assess robustness of the observed thickness anomalies. Thickness is retrieved from ice freeboard by processing CS2 Level 1B data, with a footprint of $300 \mathrm{~m}$ by $1700 \mathrm{~m}$, and assuming snow density and snow depth from the Warren et al. (1999) climatology (hereafter W99), modified for the distribution of multi-year vs. firstyear ice (i.e., snow depth is halved over first-year ice) (see Laxon et al., 2013 and Tilling et al., 2017 for data processing details).

While the three data providers rely on W99 for snow depth and density, each institution processes the radar returns differently. In general, the range to the main scattering horizon of the radar return is obtained using a retracker algorithm. This can be based on a threshold (e.g Laxon et al., 2013; Ricker et al., 2014; Hendricks et al., 2016) or a physical retracker (Kurtz et al., 2014). While the CPOM and AWI products use a leading edge $70 \%$ threshold retracker, Kurtz and Harbeck (2017) rely on a physical model to best fit each CryoSat-2 waveform. This will lead to ice thickness differences based on different thresholds applied: Kurtz et al. (2014) found a $12 \mathrm{~cm}$ mean difference between using a $50 \%$ threshold and a waveform fitting method.

We note that several factors contribute to CS2-derived sea ice thickness uncertainties, including the assumption that the radar return is from the snow or ice interface (Willat et al., 2011), snow depth departures from climatology and the use of fixed snow and ice densities. In this study we initialize the CICE model simulations described below with the CPOM sea ice thickness fields. Accuracy of the CPOM product has been evaluated in several studies, suggesting mean biases between thickness observations in 2011 and 2012 of $6.6 \mathrm{~cm}$, when compared with airborne EM data (Laxon et al., 2013; Tilling et al., 2015). For April 2017, the CPOM near-realtime product (Tilling et al., 2016) was used in place of the archived product, with a mean thickness bias of $0.9 \mathrm{~cm}$ between these products.

In this study, individual thickness point measurements are binned into 5 CICE thickness categories $(1:<0.6 \mathrm{~m}, 2: 0.6-$ $1.4 \mathrm{~m}, 3: 1.4-2.6 \mathrm{~m}, 4: 2.6-3.6 \mathrm{~m}, 5:>3.6 \mathrm{~m})$ on a rectangu- 
lar $50 \mathrm{~km}$ grid for each month. The mean area fraction and mean thickness is derived for each thickness category and these values are interpolated on the tripolar $1^{\circ} \mathrm{CICE}$ grid ( $\sim 40 \mathrm{~km}$ grid resolution). Grid points with less than $100 \mathrm{in}-$ dividual measurements and a mean SIT $<0.5 \mathrm{~m}$ are not included. Otherwise, all individual observations are included. For November, this effectively limits the area of the Arctic to the region shown in Fig. 1c. Negative thickness values that are retained in the CS2 processing to prevent statistical positive bias of the thinner ice are added to category 1 . The novel approach of initializing the CICE model with the full ITD rather than the mean sea ice thickness provides an additional control on the repartition of the ice among different thickness categories. This in turn allows a more accurate representation of ice growth and ice melt processes (Tsamados et al., 2015) compared to initializing with the mean grid-cell SIT and deriving the fractions for each ice category assuming a parabolic distribution. Ice growth and melt strongly depend on SIT: using a real distribution can have a big impact, especially for thin ice.

\subsection{CICE simulations}

CICE is a dynamic thermodynamic sea ice model designed for inclusion within a global climate model. The advantages of using CICE for this study is that we can more readily separate thickness anomalies into their thermodynamic and dynamical contributions, examine inter-annual variability and perform longer simulations. For this study, we performed two different CICE simulations. The first is a multi-year simulation from 1985 to 2017 (referred to as CICE-free). The second is a stand-alone sea ice simulation for the pan-Arctic region starting in mid-November and running until the end of April of the following year for the last seven winter periods from 2010/2011 to 2016/2017. This results in seven 1-year long simulations (referred to as CICE-ini), in which the initial thickness and concentration for each of the five ice categories is updated from the CS2 ITD using the CPOM CS2 November thickness fields. For grid points without CS2 data, and for all other variables (e.g., temperature profiles, snow volume), results from the free CICE simulation with the same configuration, started in 1985, are applied. In this way, CICE simulations cover the pan-Arctic region, but in regions where no $\mathrm{CS} 2$ are available, we restart SIT values from the free CICE model run. While this approach would be problematic in a coupled model, in a stand-alone sea ice simulation the model adjustment to the new conditions is smooth and the impact of using the vertical temperature profile from the free simulation only affects sea ice thickness in the order of millimeters.

Snow accumulation can depart strongly from the W99 climatology for individual years. Thus, we make the assumption that the deviation of the mean annual cycle of snow depth over the last 7 years from the W99 climatology is small and assume mean winter ice growth to be determined accu- rately from $\mathrm{CS} 2$, and tuned CICE-ini accordingly to match the observed CS2 mean winter ice growth from the CPOM product in the central Arctic (Fig. 1). The excellent agreement for both CICE-ini and CICE-free with CS2 increases the confidence of our model results. Therefore, our approach allows us to study inter-annual variability from two model configurations with different sources of errors, in addition to the three CS2-based products.

For both CICE simulations, NCEP-2 provides the atmospheric forcing. We use NCEP-2 $2 \mathrm{~m}$ air temperatures because they have been shown to be more realistic for the Arctic Ocean than those from ERA-Interim (Jakobshavn et al., 2012). The setup is the same as described in Schröder et al. (2014), including a simple ocean-mixed layer model, a prognostic melt pond model (Flocco et al., 2012) and an elastic anisotropic-plastic rheology (Tsamados et al., 2013), with the following improvements: we apply an updated CICE version 5.1.2 with variable atmospheric and oceanic form drag parameterization (Tsamados et al., 2014), we increase the thermal conductivity of fresh ice from 2.03 to $2.63 \mathrm{~W} \mathrm{~m}^{-1} \mathrm{~K}^{-1}$, snow from 0.3 to $0.5 \mathrm{~W} \mathrm{~m}^{-1} \mathrm{~K}^{-1}$ and the emissivity of snow and ice from 0.95 to 0.976 . While the default conductivity values are at the lower end of the observed range, the new values are at the upper end and have been applied in previous climate simulations (e.g., Rae et al., 2014).

Below, all CS2-derived sea ice thickness anomalies are computed relative to the CS2 time-period: November anomalies are relative to 2010-2016 and for April they are relative to 2011-2017. Results for November and April are only shown for all grid cells that have a minimum thickness of $50 \mathrm{~cm}$ and a minimum of 100 individual measurements for each of the seven years. For the month of November, this corresponds to all colored areas shown in Fig. 1c. For April, this region represents the area in red shown in Fig. 1d. The larger region shown in Fig. 1d also corresponds to the region over which the amount of thermodynamic ice growth and dynamical ice growth between November and April are assessed from the CICE simulations. For comparison with CS2, we present the mean thickness of the ice-covered area. In winter, the sea ice concentration in the model generally ranges between 0.98 and $0.995 \%$ apart from locations close to the ice edge. Further note that area-averaged values for November and April are only given for regions shown in Fig. 1c and d, respectively.

\section{Results}

\subsection{Air temperature and freezing anomalies}

The growing season air temperature anomalies (i.e., midNovember 2016 to mid-April 2017, relative to 1981-2010) were positive throughout the Arctic, leading to large reductions in the number of FDDs, computed as the cumulative daily $2 \mathrm{~m}$ NCEP-2 air temperatures below $-1.8^{\circ} \mathrm{C}$, similar to 

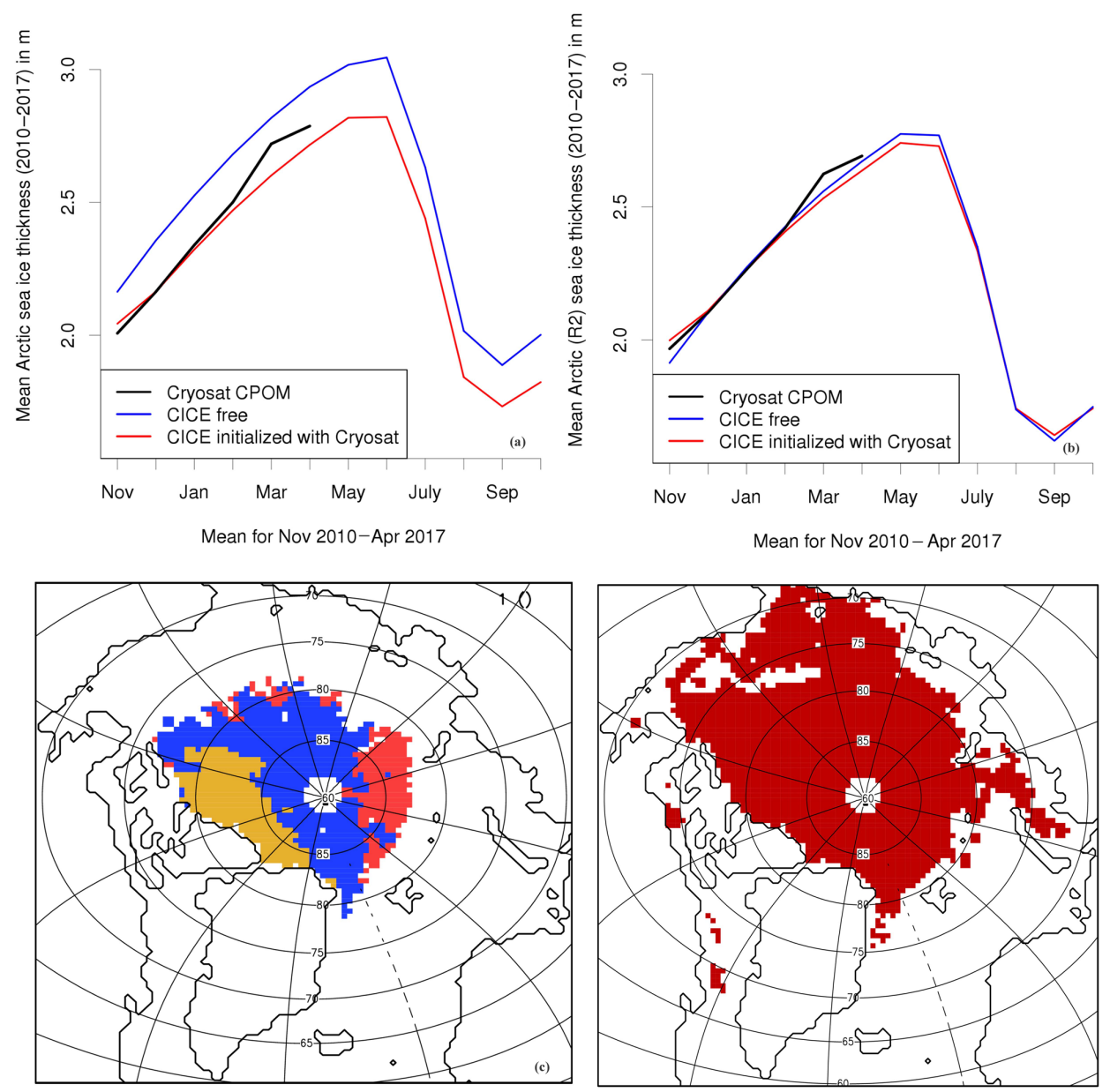

Figure 1. Comparison of CPOM CryoSat-2 mean seasonal sea ice thickness (black) with CICE free (blue) and CICE initialized with Cryosat2 in November (red). Panel (a) shows results for mean thickness, averaged over all the colored areas shown in panel (c), representing the total region for which Cryosat-2 data exist in November (only grid points included with $>100$ measurements per month and mean thickness $>0.5 \mathrm{~m}$ ) and (b) mean thickness averaged over the sub-region shown in blue with medium thick ice in January (between 1.5 and $2.5 \mathrm{~m}$ ). Blue areas in panel (c) show regions between November and January where CryoSat-2 thickness are between 1.5 and $2.5 \mathrm{~m}$ in all years; red for thin ice $(<1.5)$ and orange for thick ice $(>2.5 \mathrm{~m})$. Panel $(\mathbf{d})$ is the region over which the April thickness anomalies and results are presented.

Ricker et al. (2017a). FDDs computed this way reflect both the number of days with air temperatures below freezing and the magnitude of below freezing air temperatures over the specified period. Spatially, FDD anomalies show widespread reductions over most of the Arctic Ocean, with the largest reductions in the Barents and Kara seas, stretching across the pole towards the Beaufort and Chukchi seas (Fig. 2b). In contrast, during winter 2015/2016, FDDs were most notably anomalous within the Barents and Kara seas (Fig. 2a), in agreement with Ricker et al. (2017a). Overall, as averaged from $70-90^{\circ} \mathrm{N}$, winter 2016/2017 witnessed the least amount of cumulative FDDs since at least 1979 (Fig. 2c).

While ice forms quickly within the central Arctic once air temperatures drop below freezing, 2016/2017 saw large delays in freeze-up throughout the Arctic. Updating results previously reported in Stroeve et al. (2014), freeze-up was de- layed by 20 days for the Arctic as a whole, with regions like the Bering, Beaufort, Chukchi, East Siberian and Kara seas delayed by 3 to 4 weeks (Fig. 2d). Within the Barents Sea, the regionally averaged freeze-up was delayed by 60 days. In recent years, the trend towards later freeze-up has increased, with the Barents and Chukchi seas showing the largest trends in the order of +14 days per decade through 2017, followed by the Kara and East Siberian seas with delays in the order of +10 to +12 days per decade. Within the Beaufort Sea, freeze-up is now happening later by +9 days per decade (Table 1).

\subsection{November ice thickness anomalies}

Before analyzing how the reduced number of freezing degree days impacted winter ice growth during 2016/2017, it is 

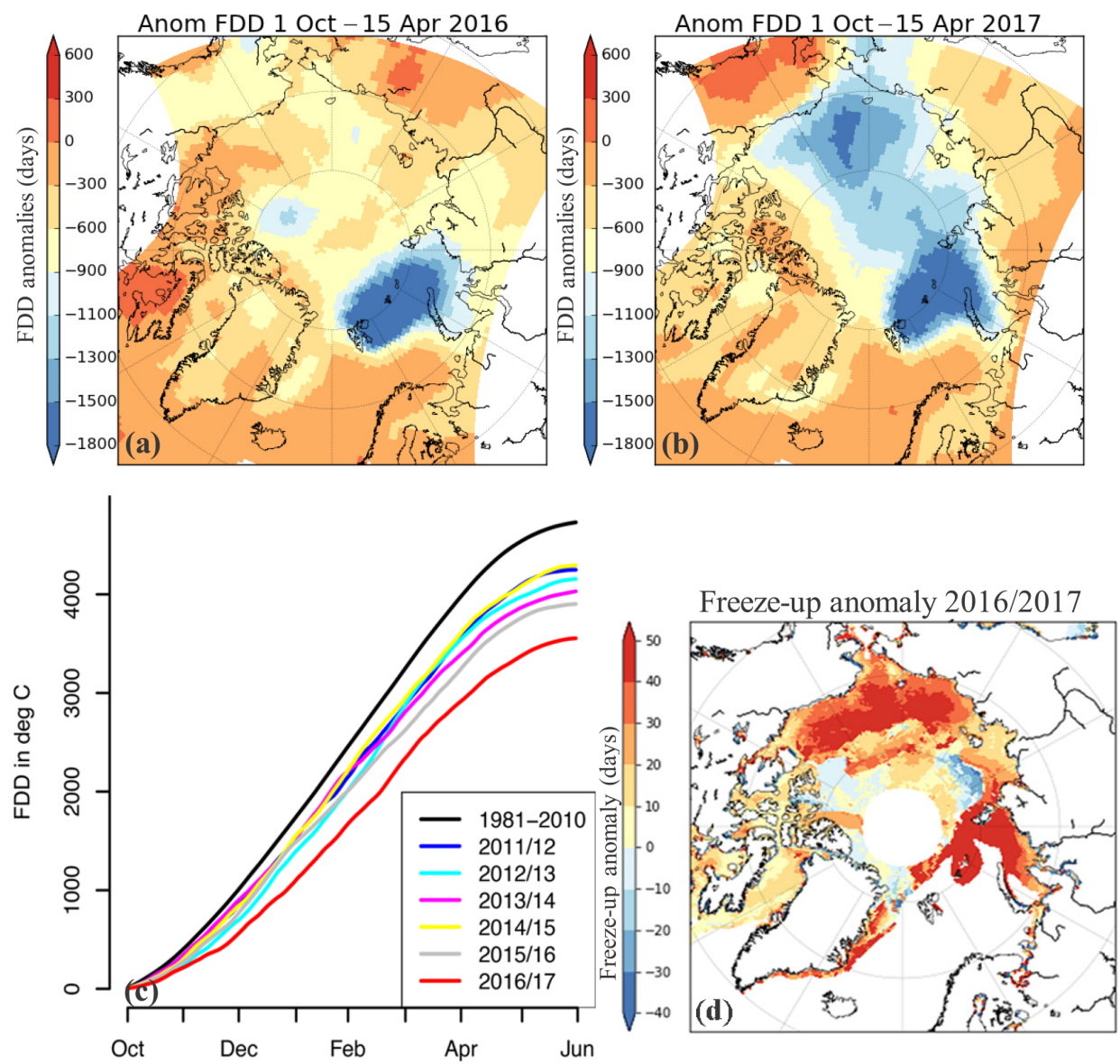

Figure 2. The top two panels show the freezing degree anomalies (FDD), computed as the number of days with NCEP2 $2 \mathrm{~m}$ air temperature below $-1.8^{\circ} \mathrm{C}$ from mid-November to mid-April in winter 2016 (a), and winter 2017 (b), computed relative to the 1981-2010 climatology. The bottom left image shows the cumulative freezing degree days (FDDs) averaged over region shown in Fig. 3 inset (c), and the bottom right image shows freeze-up anomalies for 2016/2017 relative to 1981-2010 (d). Areas in white are either missing (pole hole) or no sea ice in winter 2016/2017.

useful to first intercompare the different CryoSat-2 thickness estimates. We start with a comparison of November thickness from the three CS2 data sets from November 2010 to 2016 (Fig. 3). It is encouraging to find that year-to-year variability in the spatial patterns of positive and negative thickness anomalies are generally consistent between the three products despite differences in waveform processing. The AWI and CPOM data sets are in better agreement with each other than with the NASA product, which is expected as they use a similar retracker. Furthermore, all three data sets show widespread thinner ice in November 2011, and widespread thicker ice in November 2013. This is further supported by analysis of regional mean thickness and anomalies computed over the region shown in Fig. 1c (Table 2). For comparison, we also list results from the CICE-free model simulation. In November 2011, the different CS2 data products are in agreement that the ice was anomalously thin $(-32$ to $-46 \mathrm{~cm})$, the thinnest in the CS2 data record. Similarly, in Novem- ber 2013, all three CS2 products show overall thicker ice in the order of +23 to $+38 \mathrm{~cm}$. The CICE-free simulations also show anomalously thinner and thicker ice during these years, but larger anomalies were simulated in 2012 and 2014.

While the overall pattern of years with anomalously thin or thick ice is broadly similar between the three CS2 products, this is not true in 2016. Both the CPOM and AWI thickness estimates suggest slightly thicker ice than average $(+4$ and $+9 \mathrm{~cm}$, respectively), while the NASA product suggests the ice pack was overall slightly thinner $(-1 \mathrm{~cm})$. The CICEfree run is in agreement with the NASA data set for the 2016 anomaly. Turning back to Fig. 3, we find that in 2016 the CPOM data set shows +20 to $+60 \mathrm{~cm}$ thicker ice north of the Canadian Archipelago (CAA) and Greenland, -20 to $-60 \mathrm{~cm}$ thinner ice on the Pacific side of the pole and +10 to $+30 \mathrm{~cm}$ thicker ice north of the Laptev Sea. These spatial patterns of November 2016 SIT anomalies are broadly similar to those from AWI but less so with those from NASA. 
Table 1. Regional trends in freeze-up, 2017 freeze-up date and anomaly (relative to 1981-2010 mean). Freeze-up is computed following Markus et al. (2009).

\begin{tabular}{lrrr}
\hline Region & $\begin{array}{r}\text { Freeze-up trend } \\
\text { (days per decade) }\end{array}$ & $\begin{array}{r}2017 \text { mean freeze-up } \\
\text { (day of year) }\end{array}$ & $\begin{array}{r}\text { 2017 freeze-up } \\
\text { Anomaly (days) }\end{array}$ \\
\hline Sea of Okhotsk & 9.1 & 304 & 0.8 \\
Bering Sea & 6.7 & 338 & 25.2 \\
Hudson Bay & 7.9 & 333 & 16.9 \\
Baffin Bay & 8.0 & 312 & 13.2 \\
E. Greenland Sea & 5.6 & 267 & 2.7 \\
Barents Sea & 13.6 & 347 & 60.3 \\
Kara Sea & 10.7 & 314 & 36.6 \\
Laptev Sea & 9.0 & 272 & 10.7 \\
E. Siberian Sea & 11.8 & 286 & 27.1 \\
Chukchi Sea & 14.1 & 314 & 31.0 \\
Beaufort Sea & 8.9 & 279 & 23.4 \\
Canadian Archipelago & 4.9 & 268 & 12.7 \\
Central Arctic & 3.1 & 255 & 16.8 \\
Pan-Arctic & 7.5 & 288 & 19.6 \\
\hline
\end{tabular}

Table 2. Mean November ice thickness and anomaly with respect to the 2011-2017 mean (in parentheses) from CS2 derived from CPOM, AWI and NASA. Spatial mean is over the Arctic Basin, defined as the area for which CS-data were available continuously for all seven winter periods November to April 2010/2011 to 2016/17. This region corresponds to all three regions shown in Fig. 1c.

\begin{tabular}{lrrrr}
\hline & $\begin{array}{r}\text { November SIT } \\
\text { CS2 CPOM } \\
(\mathrm{cm})\end{array}$ & $\begin{array}{r}\text { November SIT } \\
\text { CS2 AWI }) \\
(\mathrm{cm})\end{array}$ & $\begin{array}{r}\text { November SIT } \\
\text { CS2 NASA } \\
(\mathrm{cm})\end{array}$ & $\begin{array}{r}\text { November SIT } \\
\text { CICE-free } \\
(\mathrm{cm})\end{array}$ \\
\hline 2010 & $183(-6)$ & $208(-8)$ & $198(-7)$ & $206(+6)$ \\
2011 & $157(-32)$ & $174(-42)$ & $170(-35)$ & $185(-15)$ \\
2012 & $173(-16)$ & $192(-24)$ & $177(-28)$ & $152(-48)$ \\
2013 & $212(+23)$ & $246(+29)$ & $243(+38)$ & $208(+08)$ \\
2014 & $207(+18)$ & $239(+23)$ & $226(+21)$ & $231(+31)$ \\
2015 & $196(+7)$ & $229(+13)$ & $217(+12)$ & $219(+19)$ \\
2016 & $193(+4)$ & $225(+9)$ & $204(-1)$ & $199(-1)$ \\
$2010-2016$ mean & 189 & 216 & 205 & 200 \\
\hline
\end{tabular}

However, despite similar patterns of positive and negative thickness anomalies, AWI shows between +20 and $+30 \mathrm{~cm}$ thicker ice over much of the central Arctic Ocean, and even thicker ice (up to $+60 \mathrm{~cm}$ ) north of the CAA and Greenland in November 2016, than the CPOM product. NASA, in contrast, shows larger negative anomalies on the Pacific side of the north pole of up to $-70 \mathrm{~cm}$ and larger positive anomalies directly north of the CAA between +10 and $+20 \mathrm{~cm}$.

Since we use CPOM CS2 thickness fields to initialize our CICE model runs, this comparison is useful in determining whether or not the 2016 November thickness anomalies are robust in other CS2 processing streams and provides a measure of CS2 sea ice thickness uncertainty.

However, since we do not have the AWI and NASA ITDs we cannot quantify the impact of using a different thickness data set on our simulations. However, as a result of the negative winter ice growth feedback (discussed below), differ- ences due to model initialization in November will be attenuated until April.

\subsection{Sea ice growth from November to April}

For a more robust analysis of winter ice growth during the record warm winter of 2016/2017, we now include April thickness estimates from CS2 (CPOM, AWI and NASA), the free CICE simulation and the CICE simulations initialized with CPOM CS2 November SIT in Fig. 4. Corresponding values for all other years are shown in Fig. 5 (CS2) and Fig. 6 (CICE). Table 3 summarizes associated mean April thickness and anomalies since 2011, together with contributions from thermodynamics (ice growth) and dynamics (ice transport and ridging) based on the CICE model simulations. The area for which these estimates are provided corresponds to the area shown in Fig. 1d.

We first note that all 5 estimates have different strengths and weaknesses: while the mean annual cycle of sea ice 


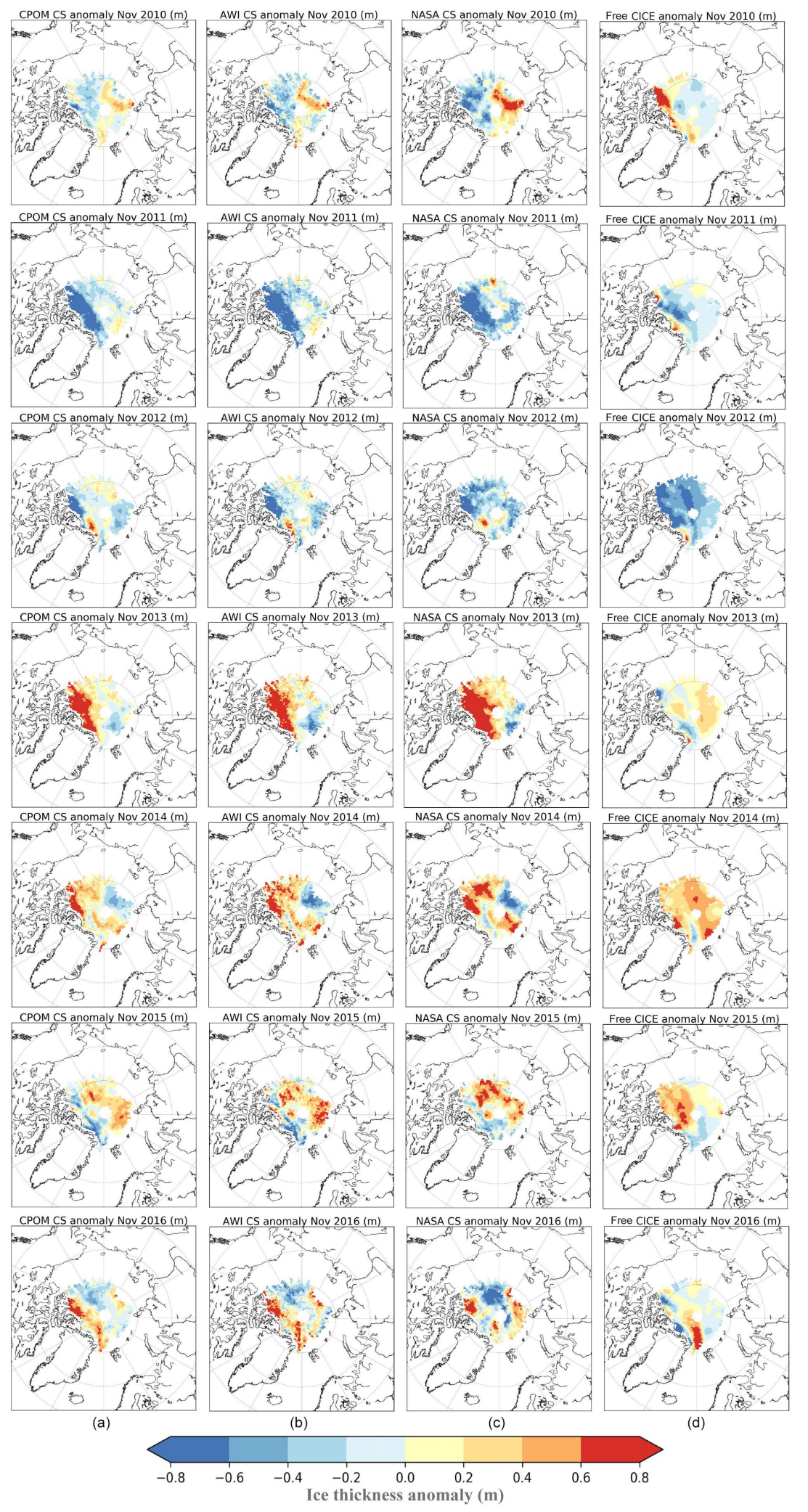

Figure 3. November ice thickness anomaly relative to 2010-2016 in $\mathrm{cm}$ based on CryoSat-2 data from UCL CPOM (a), Alfred Wegener Institute (AWI) (b) and NASA (c). Grid points with less than 100 individual measurements and a mean sea ice thickness of less than $0.5 \mathrm{~m}$ are not included. CICE-free thickness anomalies are also shown (d). 

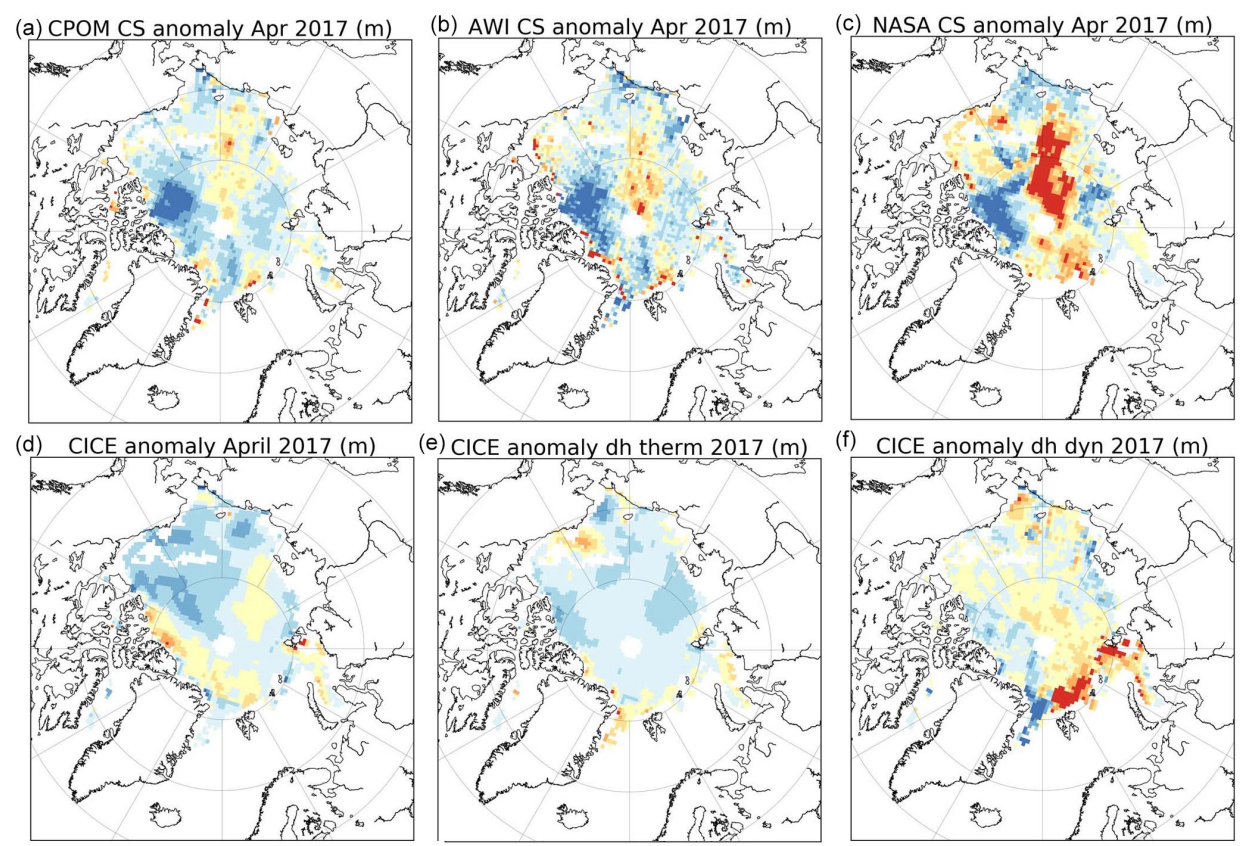

(h)Free CICE anomaly April 2017 (m) (i) Free CICE anomaly dh therm 2017(m) (j) Free CICE anomaly dh dyn 2017 (m)

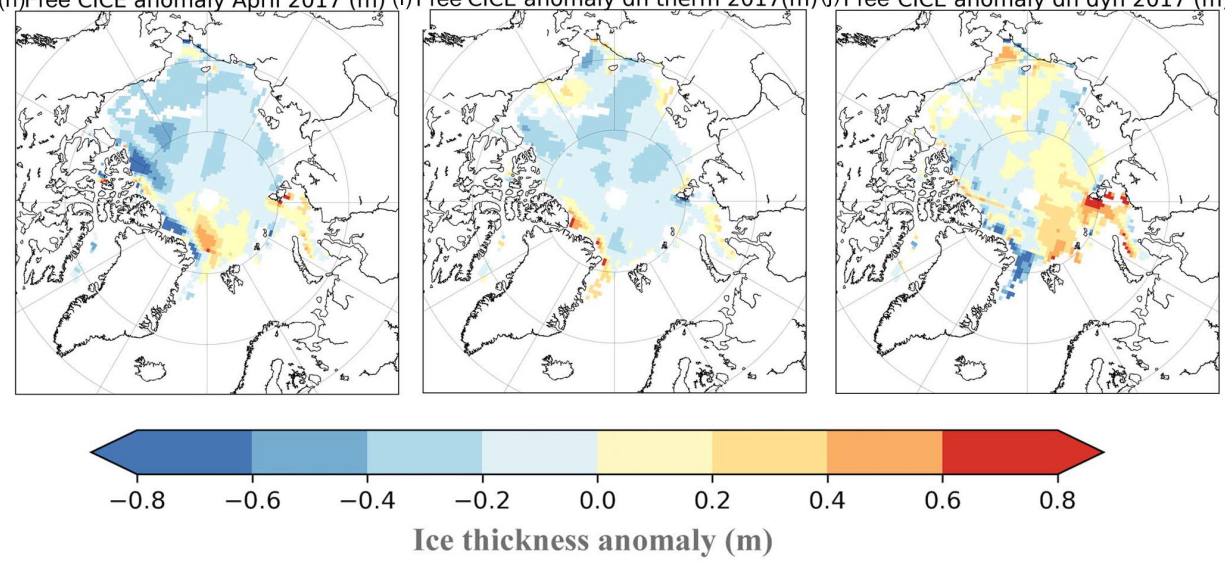

Figure 4. CryoSat-2 and CICE simulated thickness anomalies in April 2017 relative to the 2011-2017 mean. The top row of panels show the total ice thickness anomalies from CryoSat-2 for CPOM (a), AWI (b) and NASA (c). Panel (d) shows April 2017 thickness anomalies from CICE initialized with CPOM November CS2 thickness together with the contributions from thermodynamics (e) and dynamics (f) and panels $(\mathbf{h}-\mathbf{j})$ shows the corresponding results from the CICE free simulations. Grid points with less than 100 individual measurements and a mean sea ice thickness of less than $0.5 \mathrm{~m}$ are not included.

thickness should be more accurate from CS2 than modeled estimates, robust analysis of winter ice growth from CS2 is in part limited due to the impact of climatological snow depth assumptions, which may differ from one year to the next, and differences in waveform processing between CS2 data providers, which may result in inconsistencies in the magnitude and direction of the observed thickness anomalies. In the free CICE simulation, November sea ice thickness is less certain, due to error accumulation during the model run. In the initialized CICE simulation, both these error sources are reduced but inherent model biases remain. While we discuss some of the regional differences below, we are most confident in the model simulations on the Arctic basin-wide scale, over which CICE has been tuned to agree with CS2 winter ice growth.

Despite these limitations, all five approaches show good agreement in most years regarding the direction of the thickness anomalies (i.e., positive or negative) even if they disagree on absolute magnitude. For example, Arctic Ocean mean thickness anomalies are negative in all three CS2 products for April 2013 (ranging from -3 to $-25 \mathrm{~cm}$ ), whereas in April 2014 and 2015 all approaches give positive mean thickness anomalies, ranging from +5 to $+20 \mathrm{~cm}$ in 2014 and +11 to $+22 \mathrm{~cm}$ in 2015 (Table 3). In some years, the CICEfree simulation better matches the observed April thickness anomalies (e.g., 2013, 2015), whereas in other years CICE- 


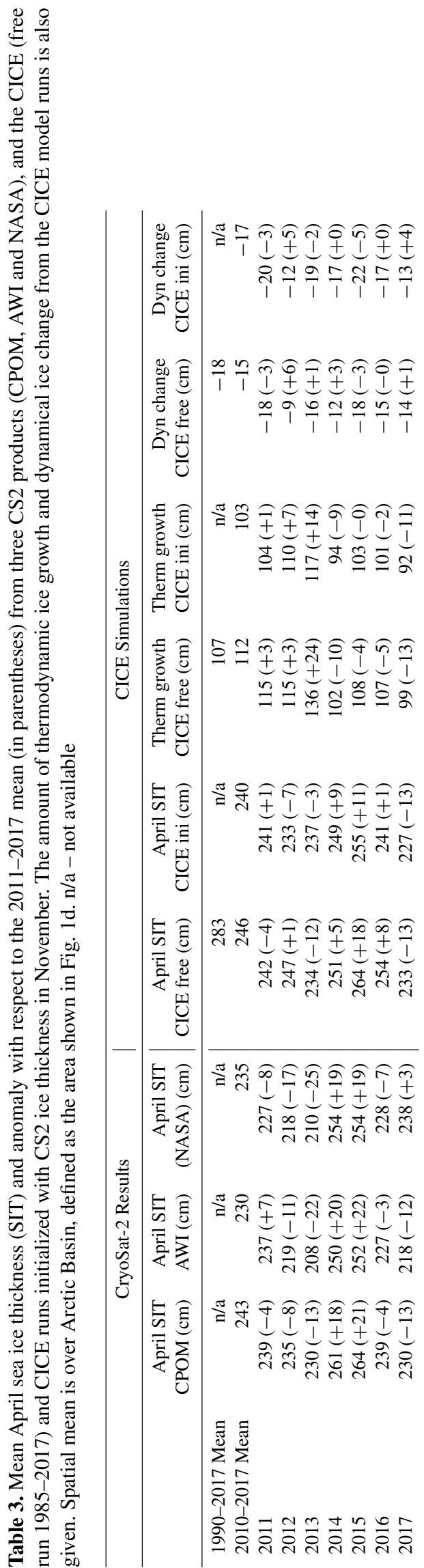

ini performs better (e.g., 2012, 2014). In contrast, in 2011 and 2017 we find disagreement among the three CS2 data sets. In April 2011, both the CPOM and NASA product have overall negative thickness anomalies for the Arctic Basin (-4 and $-8 \mathrm{~cm}$, respectively), whereas they are positive in the AWI product $(+7 \mathrm{~cm})$. In April 2017, both the CPOM and AWI are in close agreement that the ice cover was overall thinner ( -13 and $-12 \mathrm{~cm}$, respectively), as are the CICEfree and CICE-ini simulations (negative thickness anomalies of $-13 \mathrm{~cm}$ ), whereas NASA shows a weak positive anomaly $(+3 \mathrm{~cm})$.

Focusing more on April 2017, the three CS2 products suggest widespread thinner ice in April 2017 north of Ellesmere Island (up to $-80 \mathrm{~cm}$ thinner) relative to the 2011-2017 mean (Fig. 4 top). Thinner ice is also found within the Chukchi and East Siberian seas (on average -10 to $-35 \mathrm{~cm}$ thinner) despite a mix of positive and negative anomalies. CICE simulations, in contrast, show more widespread thinning throughout the western Arctic, including the Beaufort Sea and positive thickness anomalies north of Ellesmere Island (Fig. 4 middle and bottom). In the Beaufort Sea, there is general disagreement among the three CS2 products, as well as with the CS2 results and the CICE simulations: regional mean anomaly of $-5 \mathrm{~cm}(\mathrm{CPOM}), 0 \mathrm{~cm}$ (AWI), $+20 \mathrm{~cm}$ (NASA), $-25 \mathrm{~cm}$ (CICE-ini) and $-30 \mathrm{~cm}$ (CICEfree). North of Ellesmere Island, CICE-ini indicates positive thickness anomalies (up to $+50 \mathrm{~cm}$ ), whereas all $3 \mathrm{CS} 2$ products show negative thickness anomalies (up to $-80 \mathrm{~cm}$ ). In this region, the CICE-free simulation also shows mostly negative thickness anomalies $(-20$ to $-80 \mathrm{~cm})$, with a small positive area (up to $+25 \mathrm{~cm}$ ).

While the discrepancy in this region is puzzling, the bias between the CICE-ini simulations and the CS2 products may in part reflect the use of a snow climatology in the CS2 thickness retrievals. As discussed earlier, a positive sea ice thickness anomaly was found in the November 2016 CS2 thickness retrievals north of CAA and Greenland. Yet this positive thickness anomaly is not preserved through April in both the CPOM and AWI CS2 products. Figure 7 shows CICE simulated snow depth anomalies in November 2016 and April 2017. In November, small positive snow depth anomalies occur throughout the Arctic, especially north of the Queen Elizabeth Islands where the anomaly locally increases to $20 \mathrm{~cm}$. By April, the anomalies cover a broader region and increase in magnitude. A positive April snow depth anomaly of 15 to $20 \mathrm{~cm}$ relative to W99 would result in an underestimation of the CS2-retrieved April ice thickness (SIT) by 88 to $115 \mathrm{~cm}$ using the following equation:

$\mathrm{SIT}=\frac{\rho_{\text {snow }} H_{\text {snow }}+\rho_{\text {water }} F_{\mathrm{c}}}{\left(\rho_{\text {water }}-\rho_{\text {ice }}\right)}$,

where $F_{\mathrm{c}}$ is the corrected radar freeboard $\left(F_{\mathrm{b}}\right)$ for the reduced propagation of the speed of light through the snow cover $\left(F_{\mathrm{c}}=F_{\mathrm{b}}+0.25 H_{\text {snow }}\right)$ (Tilling et al., 2017), and using a snow density $\left(\rho_{\text {snow }}\right)$ of $320 \mathrm{~kg} \mathrm{~m}^{-3}$ (Warren et al., 

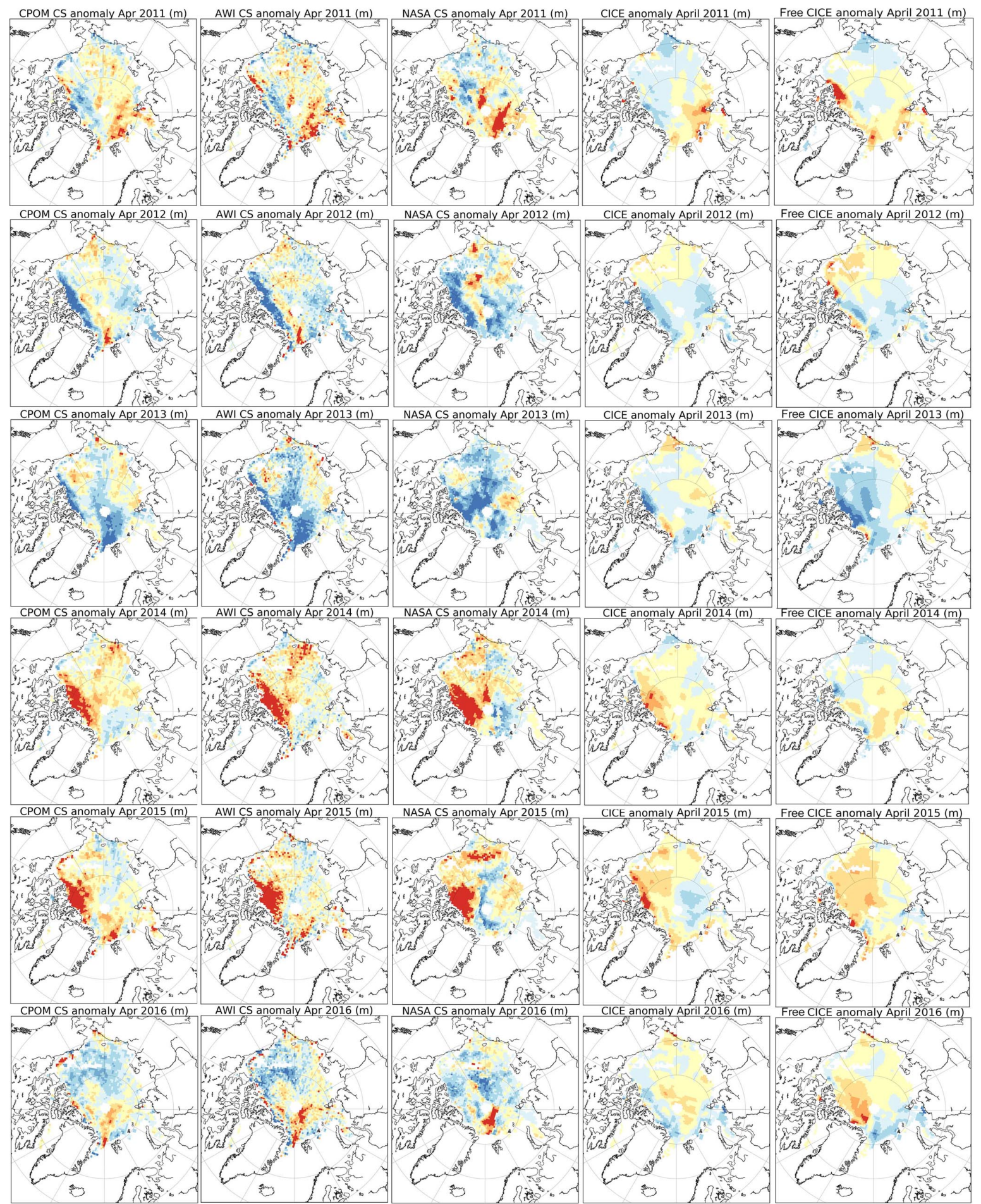

(a)
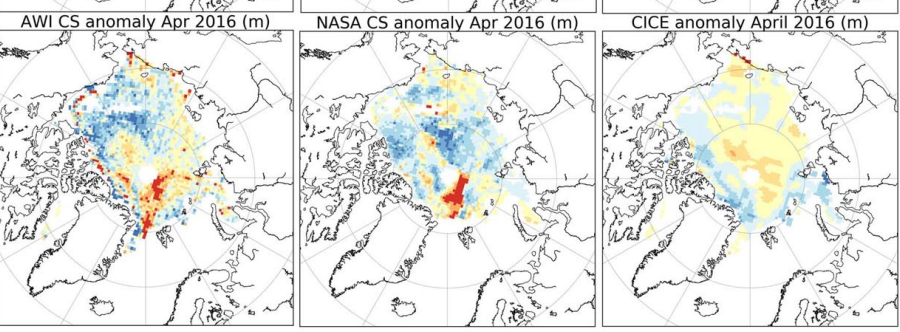

(d)

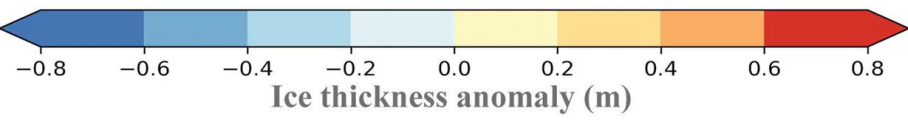

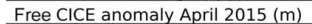
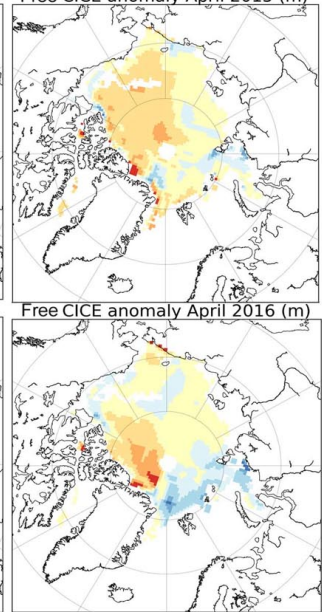

(e) (b), NASA (c), CICE simulations initialized with November CPOM CryoSat-2 thickness fields (d) and CICE simulations not initialized with CryoSat-2 thickness (e). Grid points with less than 100 individual measurements and a mean sea ice thickness of less than $0.5 \mathrm{~m}$ are not included. 

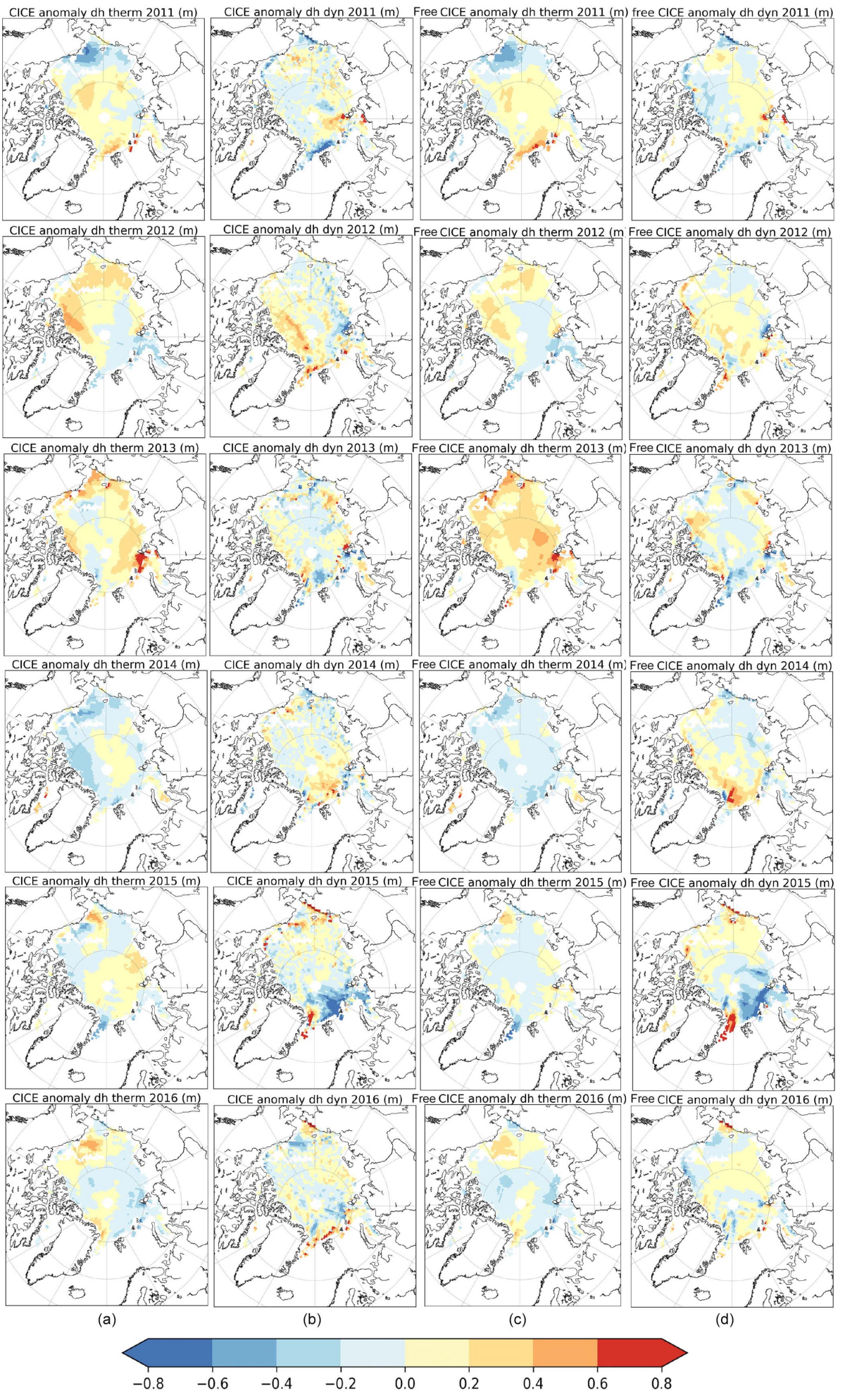

Ice thickness anomaly $(\mathrm{m})$

Figure 6. Anomalies of CICE simulated thermodynamic ice growth and dynamical thickness changes in meters relative to the 2011 to 2017 mean from the CICE simulations initialized with November CPOM CryoSat-2 thickness fields (a, b), and CICE simulations not initialized with CryoSat-2 thickness $(\mathbf{c}, \mathbf{d})$. The year in title reflects the end month over which ice growth occurs (e.g., from November to April). 

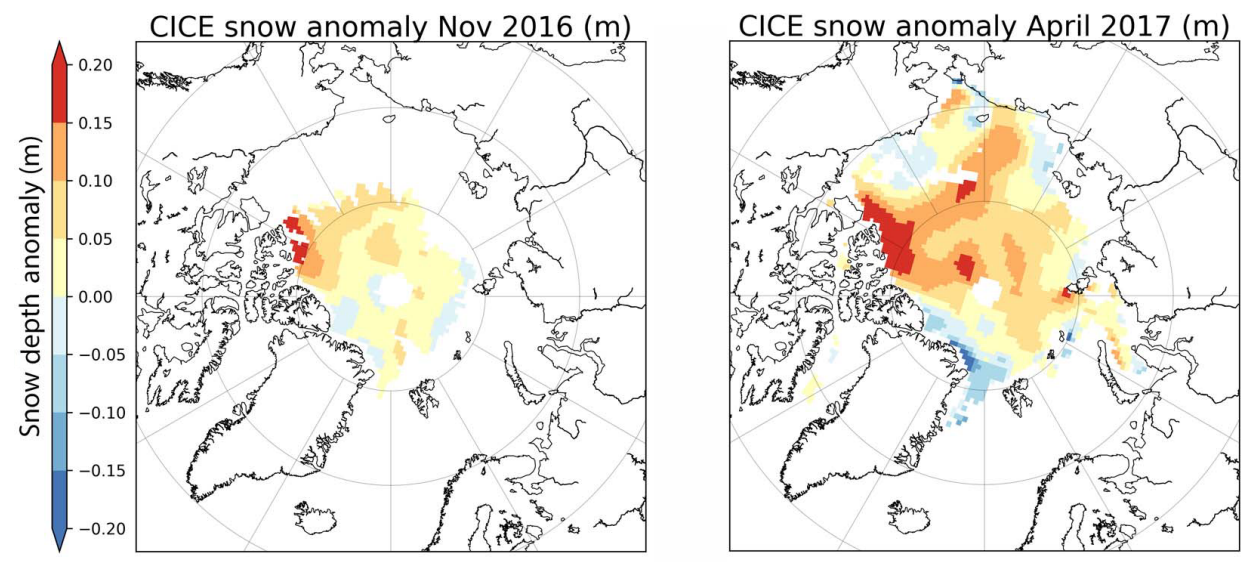

Figure 7. Snow depth anomaly for November 2016 (relative to 2010-2016) and April 2017 (relative to 2011-2017) from CICE.

1999), ice density ( $\left.\rho_{\text {ice }}\right)$ of $915 \mathrm{~kg} \mathrm{~m}^{-3}$ and water density of ( $\left.\rho_{\text {water }}\right) 1024 \mathrm{~kg} \mathrm{~m}^{-3}$. CICE-ini, which relies on the CPOM CS2 November thickness, maintains this positive thickness anomaly through April despite reduced thermodynamic ice growth. The CICE-free simulation, in contrast, started with negative thickness anomalies in November within this region, and maintains them through April.

Conversely, thickness is also strongly influenced by dynamics, such as convergence against the CAA and Greenland which leads to thicker ice in this region (Kwok et al., 2015). However, during winter 2017, the Beaufort High largely collapsed (Moore et al., 2018), reducing convergence against the northern CAA and Greenland (Fig. 8). One advantage of using CICE, is that we can more readily diagnose thermodynamic vs. dynamical contributions to the observed thickness anomalies. For the region directly north of Ellesmere Island, both the CICE-ini and CICE-free simulations support reduced sea ice convergence, leading to thinner ice from dynamical contributions. At the same time, this region also exhibited reduced thermodynamic ice growth in both CICE simulations. One would expect thermodynamic ice growth to be reduced in regions of enhanced snow depth and thicker November ice. Positive snow depth anomalies extended from this region through the northern Beaufort Sea, in agreement with extended regions reductions in thermodynamic ice growth in both CICE-free and CICE-ini. At the same time, regions of positive 2016 November thickness anomalies are also associated with regions of reduced CICE thermodynamic ice growth.

Overall, the largest reductions in thermodynamic ice growth during winter 2016/2017 occurred within the Chukchi Sea and north of the CAA, extending through the northern Beaufort Sea (in the order of $-40 \mathrm{~cm}$ ). While snow depth and thickness anomalies influenced thermodynamic ice growth north of the CCA, within the Chukchi Sea the negative ice growth anomalies were a result of late ice formation: ice formed a month later than the 1981-2010 mean within the
Chukchi Sea. This seems to have been more important than increases in ice thickness from dynamics. Dynamical thickness changes simulated by CICE show an overall thickening of the ice in winter 2016/2017 within the Chukchi and Bering seas (up to $50 \mathrm{~cm}$ ). Anomalous ridging in this region is in agreement with observed high amounts of deformation along the shore fast ice zone within the Chukchi Sea, as a result of persistent west winds from December to March (http://arcus.org/sipn/sea-ice-outlook/2017/june, last access: August 2017).

An exception to reduced thermodynamic ice growth occurs directly north of Utqiagivik, Alaska (formerly Barrow), with positive thermodynamic ice growth anomalies of 30 to $40 \mathrm{~cm}$. This enhanced ice growth was offset by ice divergence, leading to overall thinner ice in the CICE simulations. In situ observations of level first-year ice thickness off the coast of Utqiagivik ranged between 1.35 and $1.40 \mathrm{~m}$ during May (http://arcus.org/sipn/sea-ice-outlook/ 2017/june, last access: August 2017) and appear to be in better agreement with the CICE simulations, as well as the CPOM and AWI CS2 thickness estimates, while the NASA CS2 product shows positive thickness anomalies in that region. Positive thermodynamic ice growth anomalies are also found for small regions north of Greenland and within Fram Strait, as well as within some scattered coastal regions of the Chukchi, East Siberian, Laptev and Kara seas.

Finally, large dynamical thickening was found within the Kara and northern Barents seas (up to $1.2 \mathrm{~m}$ ) and to a lesser extent over the southern and western Greenland Sea, Baffin Bay and the Labrador Sea (not shown). The CICE-simulated dynamical thickening in the Barents and Kara seas is more anomalous than seen during previous CS2 years (Fig. 6), and likely reflects the influence of the positive Arctic Oscillation (AO) on ice motion (Fig. 8). The AO was positive from December through March, a pattern which results in offshore ice advection from Siberia and enhanced ice advection through Fram Strait (Rigor et al., 2002). This pattern leads 

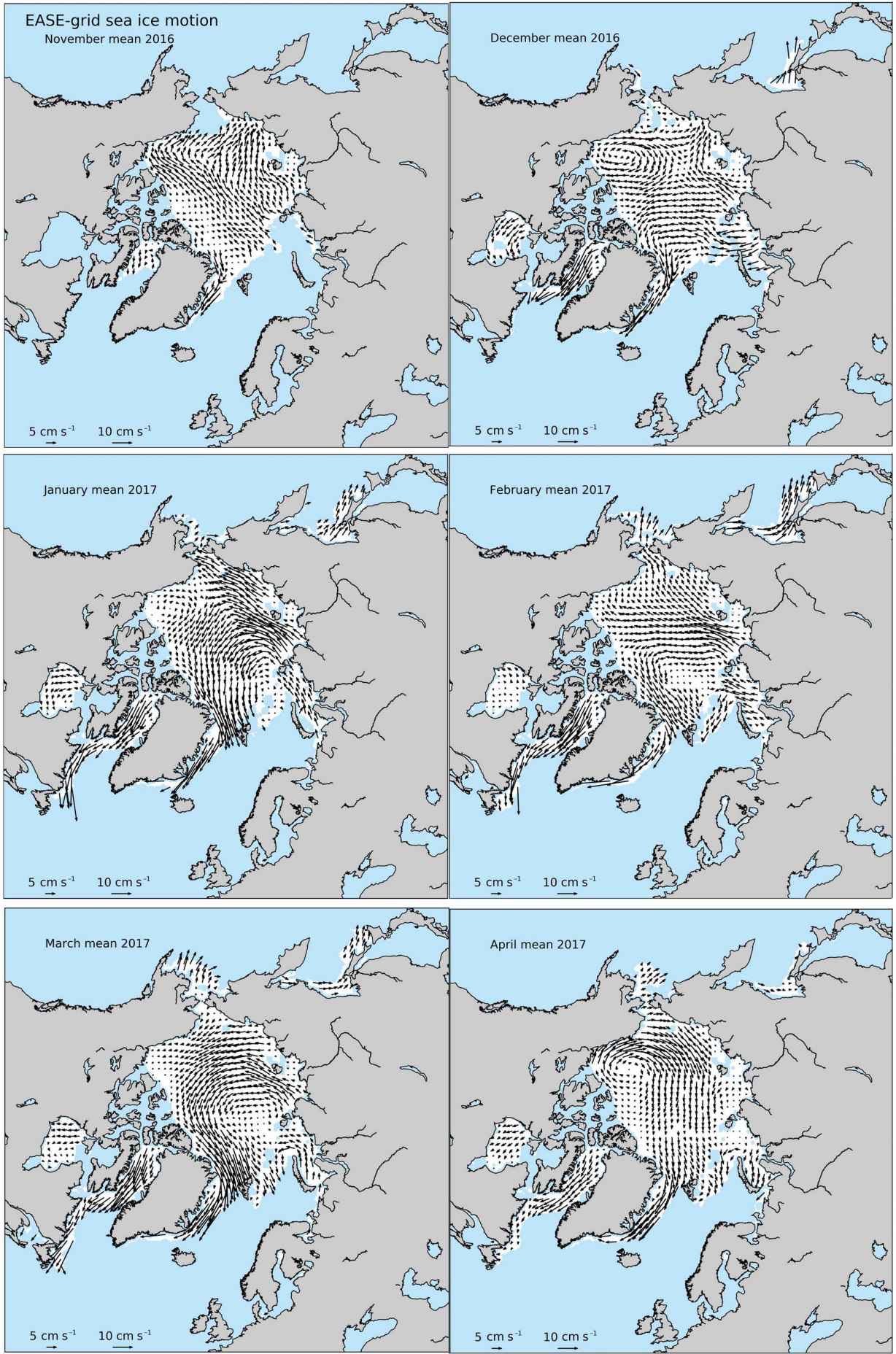

Figure 8. Mean monthly sea ice motion from the NSIDC Polar Pathfinder Data Set. Preliminary data provided by Scott Stewart, NSIDC.

to development of thin ice in newly formed open water areas, increasing thermodynamic ice growth in the Laptev Sea, whereas increased ice advection from thick ice regions north of Greenland towards Fram Strait, combined with changes in internal ice stress as the ice cover has thinned, leads to more deformation. Interestingly, while the CICE model runs confirm overall slightly thinner ice within the Barents Sea in April 2016, consistent with the studies by Ricker et al. (2017a) and Boisvert et al. (2016), the thinning from reduced thermodynamic ice growth was largely offset by thickening from dynamical effects (Figs. 5 and 6). 

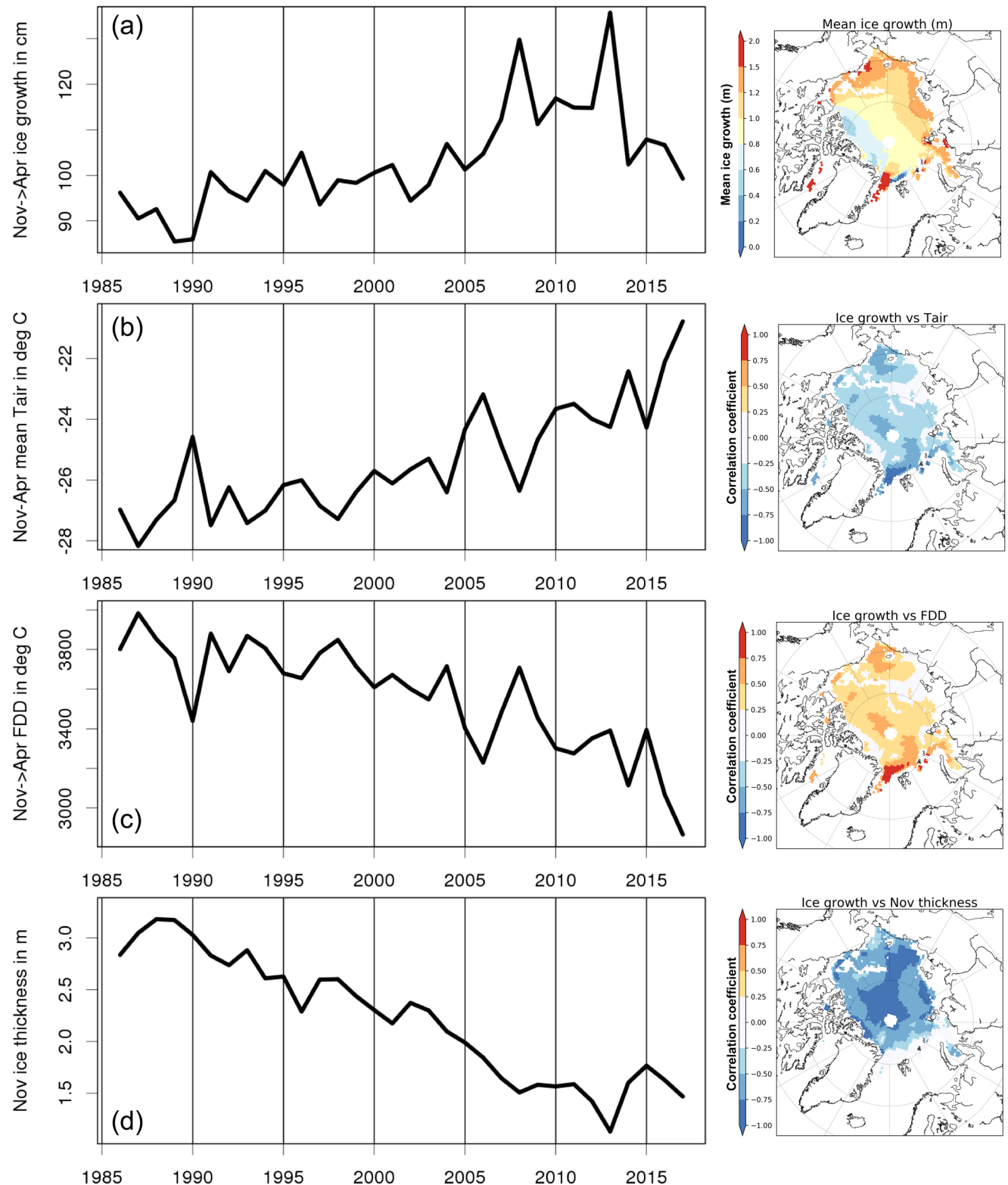

Figure 9. Time-series from 1985 to 2017 of mean winter ice growth (mid-November to mid-April) in the free CICE simulation (a), mean $2 \mathrm{~m} \mathrm{NCEP-2}$ air temperature (b), cumulative freezing degree days (FDDs) (c) and November ice thickness (d). All time-series results are averaged over the areas shown in Fig. 1c. Corresponding images to the left of each time-series plots show the following: mean ice growth from November to April as averaged from 1985/1986 to 2016/2017; correlation coefficient between ice growth and 2 m NCEP-2 air temperature; correlation coefficient between ice growth and FDDs; and correlation coefficient between ice growth and November ice thickness, respectively. All correlation values are given for linear regression of de-trended time series.

Overall, for the Arctic Basin as a whole, CICE simulations suggest the overall thinner ice observed in April 2017 is largely result of reduced thermodynamic ice growth $(-11$ to $-13 \mathrm{~cm}$ ), with dynamics adding +1 to $+4 \mathrm{~cm}$ (Table 3 ).

\subsection{Negative feedbacks}

Ice growth after the September minima is a result of turbulent heat flux exchanges between the relatively warm ocean mixed layer and the cold autumn and winter air through the snow-covered sea ice. Progressively, as the ice grows to about 1.5 to $2 \mathrm{~m}$ thick, the ocean becomes well insulated from the atmosphere and ice growth is slowed. Thus, it is not surprising that we see less thermodynamic ice growth in regions of relatively thick $(>2.5 \mathrm{~m}$ ) November ice. A case in point is seen in winter 2013/2014 when thermodynamic ice growth was reduced by 9 to $10 \mathrm{~cm}$, despite an overall colder winter. 


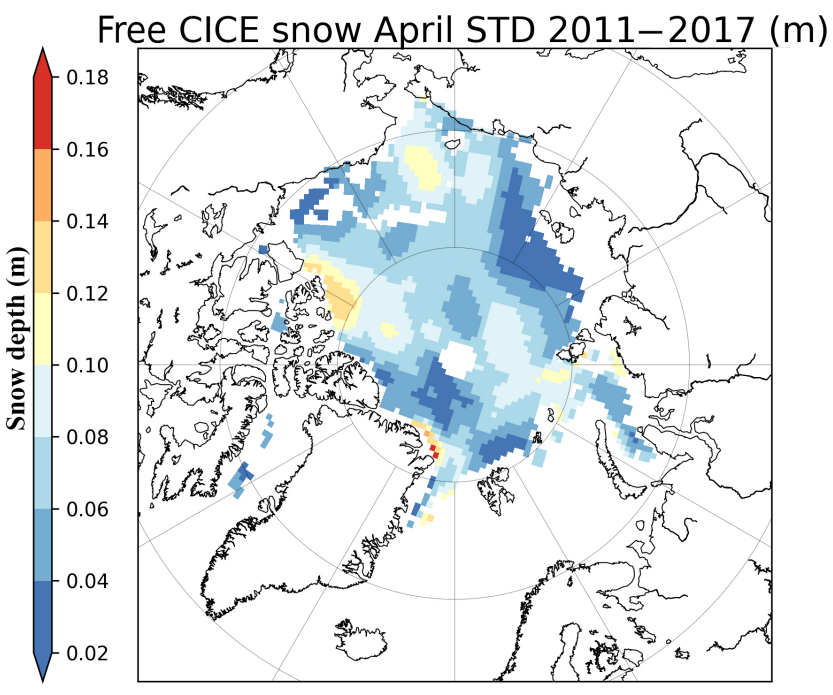

Figure 10. Standard deviation of CICE-simulated snow depth using NCEP-2 reanalysis for the month of April from 2011 to 2017.

Conversely, thinner ice regions generally exhibit more vigorous ice growth. For example, during winter 2012/2013, CICE-free, and to a lesser extent CICE-ini simulated thermodynamic ice growth increased throughout much of the Arctic Ocean in areas where the ice retreated in September 2012 (Fig. 6) and where the November 2012 thickness anomalies were negative (Fig. 3). This process of rapid winter ice growth over thin ice regions represents a negative feedback, allowing for ice to form quickly over large parts of the Arctic Ocean following summers with reduced ice cover and thinner November ice.

Thus, while summer sea ice is rapidly declining, several studies have indicated negative feedbacks over winter continue to dominate (e.g., Notz and Marotzke, 2012; Stroeve and Notz, 2015), allowing for recovery following summers with anomalously low sea ice extent, such as those observed in 2007 and 2012. This is further supported in the CICEfree simulations which show the least amount of winter ice growth for the Arctic Basin in 1989, and peak ice growth following the 2007 and 2012 record minimum sea ice extent (Fig. 9). As a result, mean ice growth from November to April in CICE simulations from 1985 to 2017 shows a positive trend that is weakly correlated to winter air temperatures or FDDs $(R=0.49)$. Conversely, we find a strong inverse correlation $(R=-0.82)$ between November sea ice thickness and winter ice growth. Thus, because thin ice grows faster than thick ice, there is an overall stabilizing effect that suggests as long as air temperatures remain below freezing, even if they are anomalously warm, the ice can recover during winter. This stabilizing feedback over winter means that major departures of the September sea ice extent from the long-term trend caused by summer atmospheric variability generally does not persist for more than a few years (Serreze and Stroeve, 2015).

However, since 2012, overall ice growth has declined as winter air temperatures have increased further. This not surprising in that there was a lot of new ice to form in the open waters left after the 2012 record minima. However, 2016 tied with 2007 for the second lowest Arctic sea ice minimum and overall thermodynamic ice growth was significantly less. The correlation from 1985 to 2012 is smaller than over the full record $(R=0.34)$, suggesting a growing influence of warmer winter air temperatures though the difference in correlation is not statistically significant. While there remains a large amount of inter-annual variability in winter warming events, Graham et al. (2017) suggest a positive trend in not only the maximum temperature of these warming events, but also in their duration. Interestingly, there is a modest correlation between detrended FDDs and the winter maxima sea ice extent $(R=0.30)$; not removing the trend results in a correlation of $R=0.83$. Thus, recent reductions in overall FDDs may have played a role in the last three years of record low maxima extents.

\section{Discussion}

The CICE-simulations and CS2 thickness retrievals from CPOM and AWI show consistency that the Arctic Basin sea ice cover in April 2017 was on average $13 \mathrm{~cm}$ thinner than the 2011-2017 mean. However, it may not have been the thinnest during the CS2 data record. Thickness retrievals from the different CS2 data sets showed larger negative thickness anomalies in April 2013, ranging from - 13 to $-25 \mathrm{~cm}$, whereas the CICE simulations showed smaller anomalies $(-3$ to $-12 \mathrm{~cm}$ ). While we expect retrievals from the satellite to be more accurate than those from model simulations, whether or not a year is anomalously low relative to another year will depend in part on the inter-annual variability in the snow cover. All three CS2 products rely on the W99 snow depth climatology. While Haas et al. (2017) found snow depth within the Lincoln Sea in 2017 was similar to W99, evaluation of reanalysis data shows considerable variability in total precipitation from year to year (Barrett et al., 2018). In the CICE-free simulations, snow depth is modeled using precipitation from NCEP-2. Inter-annual variability from April 2011 to April 2017 (calculated as standard deviation between the seven monthly April means) is shown in Fig. 10. North of the CAA, standard deviations in snow depth are in the order of 12 to $14 \mathrm{~cm}$, whereas other regions are in the order of 2 to $12 \mathrm{~cm}$. From the W99 climatology, interannual variability in snow depth during the winter months was estimated to be only 4 to $6 \mathrm{~cm}$, significantly less than what is exhibited here. Since ice thickness increases approximately 6 times the snow depth uncertainty, a 12 to $14 \mathrm{~cm}$ uncertainty would lead to 72 to $83 \mathrm{~cm}$ increase in CS2-derived ice thickness. If we average for the area shown in Fig. 1d, 

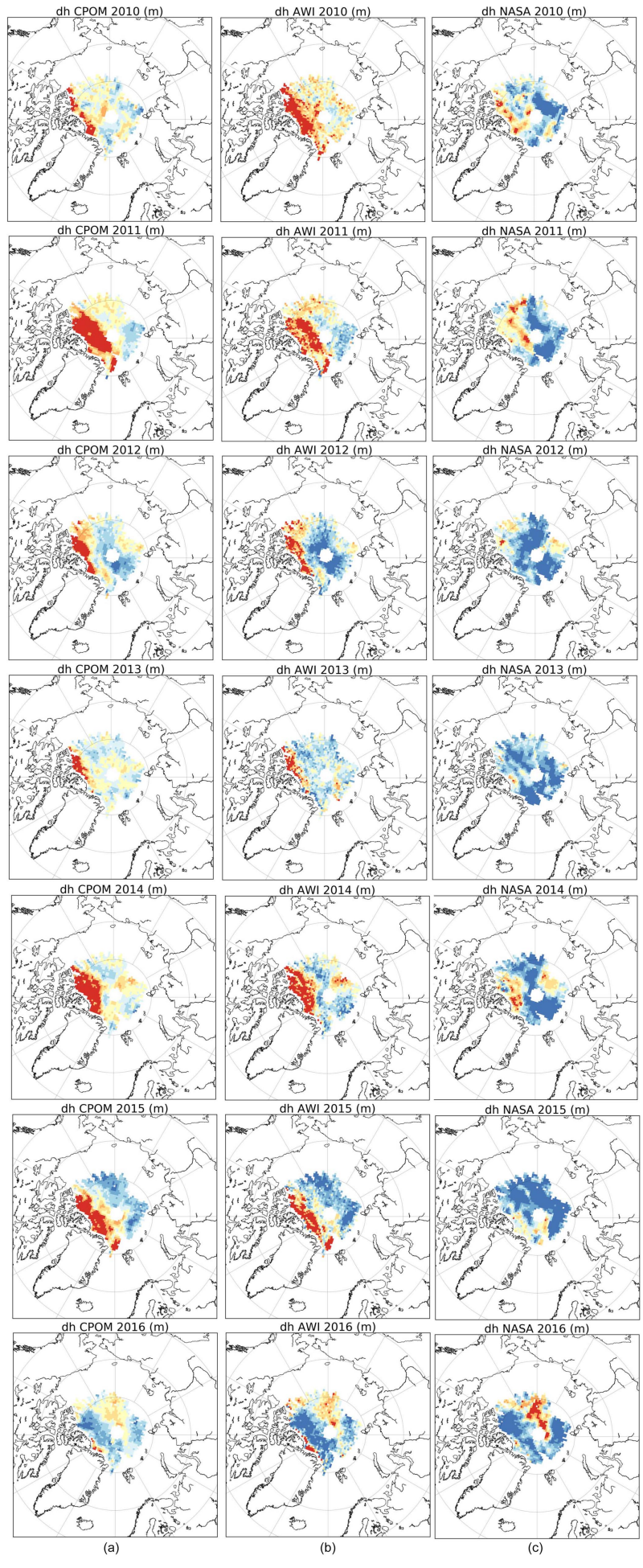

Figure 11. Comparison between ice growth (April minus November) in the UCL CPOM CryoSat-2 thickness retrievals (a) and those from the Alfred Wegener Institute (AWI) (b) and NASA (c). The year shown corresponds to the November months, such that 2016 refers to ice thickness differences between April 2017 and November 2016. Results are only shown for the area shown in Fig. 1c, which represents grid points that had more than 100 individual measurements and a mean sea ice thickness greater than $0.5 \mathrm{~m}$ during the November months. 
snow depth anomalies ranged from -6 to $+6 \mathrm{~cm}$, with a corresponding impact of -41 to $+41 \mathrm{~cm}$ on thickness.

Besides not accounting for inter-annual variability in snow depth, which makes assessing thickness anomalies from one year to the next less certain, differences in waveform processing between the three different CS2 products adds further uncertainty. The fact that the NASA CS2 product is a general outlier compared to the AWI and CPOM products is further highlighted in Fig. 11. Across the area considered (e.g., areas in color shown in Fig. 1c), the difference between April and the previous November ice thickness is shown for each CryoSat-2 year. The AWI and CPOM products tend to exhibit positive ice growth over winter, focused north of Greenland and the CAA and sometimes also across the pole. The NASA product, in contrast, generally shows less ice growth between November and April in most years and even no ice growth in some regions. The reasons for this are unclear, yet interestingly in winter 2016/2017, all three products show more agreement in regards to thickness decreases that span a broad region north of Greenland and the CAA, combined with positive increases south of the pole towards the East Siberian and Laptev seas.

Finally, how important were the April thickness anomalies in the evolution of the summer ice cover in summer 2017? Several studies have discussed how thin winter ice may precondition the Arctic for less sea ice at the end of the melt season as thinner ice melts and open water areas form more readily in summer, enhancing the ice albedo feedback (e.g., Stroeve et al., 2012; Perovich et al., 2008), and sea ice thickness has been used as a predictor for the September sea ice extent (Kimura et al., 2013). Thus, we may have expected 2017 to be among the lowest recorded sea ice extents as the ice cover was likely thinner than average and the winter extent was the lowest in the satellite record. Nevertheless, the minimum extent ended up as the 8 th lowest in the satellite data record. This highlights the continuing importance of summer weather patterns in driving the September minimum. Spring and summer 2017 were dominated by several cold core cyclones, leading to near average air temperatures and ice divergence (see http://nsidc. org/arcticseaicenews/, last access: August 2017, for a discussion of this summer's weather patterns). Overall, the correlation between detrended winter sea ice thickness anomalies and September sea ice extent remains low (Stroeve and Notz, 2015). Other factors, such as melt pond formation in spring (Schröder et al., 2014) and summer weather patterns, still largely govern the evolution of the summer ice pack at current thickness levels (e.g., Holland and Stroeve, 2011). Interestingly, predictions of the monthly mean September 2017 sea ice extent based on spring melt pond fraction in May gave a value of $5.0 \pm 0.5$ million $\mathrm{km}^{2}$, whereas the observed value was 4.80 million $\mathrm{km}^{2}$ (See arcus.org/sipn/seaice-outlook/2017/june, last access: August 2017).

\section{Conclusions}

In this study we examined sea ice thickness anomalies derived from three different CS2 data products and that were simulated using CICE. Overall freezing degree days were much reduced in winter 2016/2017, and subsequent sea ice thickness estimates from CryoSat-2 in April 2017 suggest the ice was thinner over large parts of the Arctic Ocean. These results are complimented with CICE model simulations, both with and without initializing with November ice thickness distributions from CS2. While CICE simulations suggest the mean thickness within the Arctic Basin in April 2017 was the thinnest over the CryoSat-2 data record, corresponding CS2-derived sea ice thickness from the three different data providers put this into question. However, the use of CS2derived freeboards with a snow depth climatology remains problematic because it fails to capture inter-annual snow accumulation variability. Differences in processing of the radar waveform, values of snow and ice density, delineation of first-year vs. multi-year ice, and sea surface height retrieval also contribute to differences among available data sets, making it challenging to robustly assess inter-annual variability of ice thickness from CryoSat-2. Despite these challenges it is encouraging that in most years, the interannual variability in positive and negative anomalies is consistent between the three CS2 data sets.

Finally, CICE-free simulations from 1985 to 2017 reveal the correlation between winter ice growth and November ice thickness $(R=-0.82)$ is stronger than between growth and FDDs $(R=0.49)$, highlighting the importance of the negative winter growth feedback mechanism. This supports previous studies that the long-term sea ice reduction in the Arctic Basin is mainly driven by summer atmospheric conditions. However, this correlation has become weaker since 2012, indicating that higher winter air temperatures and further delays in autumn or winter freeze-up, due to warmer mixedlayer ocean temperatures, prohibit a complete recovery of winter ice thickness in spite of the negative feedback mechanism. This is highlighted by the fact that overall thermodynamic ice growth for winter 2016/2017 was just under $1 \mathrm{~m}$ despite 2016 reaching the second lowest minimum extent recorded during the satellite record.

Data availability. The AWI data are available from www. meereisportal.de, the CPOM data are available from http:// www.cpom.ucl.ac.uk/csopr/seaice.html, NASA data are available from https://nsidc.org/data/RDEFT4/, freeze-up data is available from https://neptune.gsfc.nasa.gov/csb/index.php?section=54. CICE data will be put on http://www.cpom.ucl.ac.uk/cpom_ model_Stroeve2018. NASA CryoSat-2 data provided courtesy of Nathan Kurtz. NCEP2 data obtained from NOAA Earth System Research Laboratory (http://www.esrl.noaa.gov/psd/data/gridded/ data.ncep.reanalysis2.gaussian.html, last access: May 2017). 
Competing interests. The authors declare that they have no conflict of interest.

Acknowledgements. This work was in part funded under NASA grant NNX16AJ92G (Stroeve). Sea ice simulations and CryoSat-2 satellite data processing performed under NERC funding of the Centre for Polar Observation and Modeling (CPOM). CryoSat-2 thickness fields courtesy of Andy Ridout at CPOM. Processing of the AWI CryoSat-2 (PARAMETER) is funded by the German Ministry of Economics Affairs and Energy (grant: 50EE1008) and data from November 2010 to April 2017 obtained from http://www.meereisportal.de (last access: May 2017) (grant: REKLIM-2013-04).

Edited by: Chris Derksen

Reviewed by: two anonymous referees

\section{References}

Bekryaev, R. V., Polyakov, I. V., and Alexeev, V. A.: Role of polar amplification in long-term surface air temperature variations and modern Arctic warming, J. Climate, 23, 3888-3906, 2010.

Bitz, C. M. and Roe, G. H.: A mechanism for the high rate of sea ice thinning in the Arctic Ocean, J. Climate, 17, 2623-2632, https://doi.org/10.1175/15200442(2004)017<3623:AMFTHR>2.0CO;2, 2004.

Boisvert, L. N., Petty, A. A., and Stroeve, J.: The Impact of the Extreme Winter 2015/16 Arctic Cyclone on the Barents-Kara Seas, B. Am. Meteorol. Soc., 144, 4279-4287, https://doi.org/10.1175/MWR-D-16-0234.1, 2016.

Cohen, L., Hudson, S. R., Walden, V. P., Graham, R. M., and Granskog, M. A.: Meteorological conditions in a thinner Arctic sea ice regime from winter through early summer during the 388 Norwegian young sea ICE expedition (N-ICE2015), J. Geophys. Res.-Atmos., 122, 7235-7259, https://doi.org/10.1002/2016JD026034, 2017.

Cullather, R. I., Lim, Y., Boisvert, L. N., Brucker, L., Lee, J. N., and Nowicki, S. M. J.: Analysis of the 426 warmest Arctic winter, 2015-2016, Geophys. Res. Lett., 43, 808-816, https://doi.org/10.1002/2016GL071228, 2016.

Flocco, D., Schröder, D., Feltham, D. L., and Hunke, E. C.: Impact of melt ponds on Arctic sea ice simulations from 1990 to 2007, J. Geophys. Res., 117, C09032, https://doi.org/10.1029/2012JC008195, 2012.

Graham, R. M., Cohen, L., Petty, A. A., Boisvert, L. N., Rinke, A., Hudson, S. R., Nicolaus, M., and Granskog, M. A.: increasing frequency and duration of Arctic winter warming events, Geophys. Res. Lett., 16, 6974-6983, https://doi.org/10.1002/2017GL073395, 2017.

Graversen, R. G.: Do changes in midlatitude circulation have any impact on the Arctic surface air temperature trend?, J. Climate, 19, 5422-5438, 2006.

Graversen, R. G. and Burtu, M.: Arctic amplification enhanced by latent energy transport of atmospheric planetary waves, Q. J. Roy. Meteor. Soc., 142, 2046-2054, https://doi.org/10.1002/qj.2802, 2016.
Haas, C., Beckers, J., King, J., Silis, A., Stroeve, J., Wilkinson, J., Notenboom, B., Schweiger, A., and Hendricks, S.: Ice and snow thickness variability and change in the high Arctic Ocean observed by in situ measurements, Geophys. Res. Lett., 44, 10462 10469, https://doi.org/10.1002/2017GL075434, 2017.

Hendricks, S., Ricker, R., and Helm, V.: User Guide AWI CryoSat-2 Sea Ice Thickness Data Product (v1.2), hdI:10013/epic.48201. 2016.

Holland, M. M. and Stroeve, J. C.: Changing seasonal sea ice predictor relationships in a changing Arctic climate, Geophys. Res. Lett., 38, L18501, https://doi.org/10.1029/2011GL049303, 2011.

Hunke, E. C., Lipscomb, W. H., Turner, A. K., Jeffery, N., and Elliott, S.: CICE: the Los Alamos Sea Ice Model Documentation and Software User's Manual Version 5.1, 2015.

Jakobshavn, E., Vihma, T., Palo, T., Jakobson, L., Keernik, H., and Jaagus, J.: validation of atmospheric reanalysis over the central Arctic Ocean, Geophys. Res. Lett., 39, L10802, https://doi.org/10.1029/2012GL051591, 2012.

Kanamitsu, M., Ebisuzaki, W., Woollen, J., Yang, S.-K., Hnilo, J. J., Fiorino, M., and Potter, G. L.: NCEP-DOE AMIPII Reanalysis (R-2), B. Am. Meteorol. Soc., 83, 1631-1644, https://doi.org/10.1175/BAMS-83-11-1631, 2002, updated 2017.

Kimura, N., Nishimura, A., Tanaka, Y., and Yamaguchi, H.: Influence of winter sea-ice motion on summer ice cover in the Arctic, Polar Res., 32, 20193, https://doi.org/10.3402/polar.v32i0.20193, 2013.

Kurtz, N. and Harbeck, J.: CryoSat-2 Level 4 Sea Ice Elevation, Freeboard, and Thickness, Version 1, Boulder, Colorado USA. NASA National Snow and Ice Data Center Distributed Active Archive Center, 2017.

Kurtz, N. T., Galin, N., and Studinger, M.: An improved CryoSat-2 sea ice freeboard retrieval algorithm through the use of waveform fitting, The Cryosphere, 8, 1217-1237, https://doi.org/10.5194/tc-8-1217-2014, 2014.

Kwok, R.: Sea ice convergence along the Arctic coasts of Greenland and the Canadian Arctic Archipelago: Variability and extremes (1992-2014), Geophys. Res. Lett., 42, 7598-7605, https://doi.org/10.1002/2015GL065462, 2015.

Laxon, S. W., Giles, K. A., Ridout, A. L., Wingham, D. J., Willatt, R., Cullen, R., Kwok, R., Schweiger, A., Zhang, J., Haas, C., Hendricks, S., Krishfield, R., Kurtz, N., Farrell, S., and Davidson, M.: CryoSat-2 estimates of Arctic sea ice thickness and volume, Geophys. Res. Lett., 40, 732-737, https://doi.org/10.1002/grl.50193, 2013.

Markus, T., Stroeve, J. C., and Miller, J.: Recent changes in Arctic sea ice melt onset, freeze-up, and melt season length, J. Geophys. Res., 114, C12024, https://doi.org/10.1029/2009JC005436, 2009.

Merkouriadi, I., Cheng, B., Graham, R. M., Rosel, A., and Granskog, M. A.: Critical role of snow on sea ice growth in the Atlantic sector of the Arctic Ocean, Geophys. Res. Lett., 44, 10479-10485, https://doi.org/10.1002/2017GL075494. 2017.

Moore, G. W. K., Schweiger, A., Zhang, J., and Steele, M.: Collapse of the 2017 winter Beaufort High: A response to thinning sea ice?, Geophys. Res. Lett., 45, 2860-2869, https://doi.org/10.1002/2017GL076446, 2018.

Notz, D. and Marotzke, J.: Observations reveal external driver for Arctic sea ice retreat, Geophys. Res. Lett., 39, L08502, https://doi.org/10.1029/2012GL051094, 2012. 
Overland, J. E. and Wang, M.: Recent extreme arctic temperatures are due to a split polar vortex, J. Climate, 29, 5609-5616, https://doi.org/10.1175/JCLI-D-16-0320.1, 2016.

Perovich, D. K., Richter-Menge, J. A., Jones, K. F., and Light, B.: Sunlight, water and ice: Extreme Arctic sea ice melt during the summer of 2007, Geophys. Res. Lett., 35, L11501, https://doi.org/10.1029/2008GL034007, 2008.

Pithan, F. and Mauritsen, T.: Arctic amplification dominated by temperature feedbacks in contemporary climate models, Nat. Geosci., 7, 181-184, https://doi.org/10.1038/ngeo2017, 2014.

Polyakov, I. V., Beszczynska, A., Carmack, E. C., Dmitrenko, I. A., Fahrbach, E., Frolov, I. E., Gerdes, R., Hansen, E., Holfort, J., Ivanov, V. V., Johnson, M. A., Karcher, M., Kauker, F., Morison, J., Orvik, K. A., Schauer, U., Simmons, H. L., Skagseth, A., Sokolov, V. T., Steele, M., Timokhov, L. A., Walsh, D., and Walsh, J. E.: One more step towards a warmer Arctic, Geophys. Res. Lett., 32, L17605, https://doi.org/10.1029/2005GL023740, 2005.

Rae, J. G. L., Hewitt, H. T., Keen, A. B., Ridley, J. K., Edwards, J. M., and Harris, C. M.: A sensitivity study of the sea ice simulation in HadGEM3, Ocean Model., 74, 60-76, https://doi.org/10.1016/j.ocemod.2013.12.003, 2014.

Ricker, R., Hendricks, S., Helm, V., Skourup, H., and Davidson, M.: Sensitivity of CryoSat-2 Arctic sea-ice freeboard and thickness on radar-waveform interpretation, The Cryosphere, 8, 16071622, https://doi.org/10.5194/tc-8-1607-2014, 2014.

Ricker, R., Hendricks, S., Girard-Ardhuin, F., Kaleschke, L., Lique, C., Tian-Kunze, X., Nicolaus, M., and Krumpen, T.: Satellite observed drop of Arctic sea ice growth in winter 2015-2015, Geophys. Res. Lett., 44, 3236-3245, https://doi.org/10.1002/2016GL072244, 2017a.

Ricker, R., Hendricks, S., Kaleschke, L., Tian-Kunze, X., King, J., and Haas, C.: A weekly Arctic sea-ice thickness data record from merged CryoSat-2 and SMOS satellite data, The Cryosphere, 11, 1607-1623, https://doi.org/10.5194/tc-11-1607-2017, $2017 \mathrm{~b}$.

Rigor, I. G., Wallace, J. M., and Colony, R. L.: Response of sea ice to the Arctic Oscillation, J. Climate, 15, 2648-2663, https://doi.org/10.1175/15200442(2002)015<2648:ROSITT>2.0.CO;2, 2002.

Schröder, D., Feltham, D. L., Flocco, D., and Tsamados, M.: September Arctic sea-ice minimum predicted by spring melt-pond fraction, Nat. Clim. Change, 4, 353-357, https://doi.org/10.1038/NCLIMATE2203, 2014.
Screen, J. A. and Simmonds, I.: The central role of diminishing sea ice in recent Arctic temperature amplification, Nature, 464, 1334-1337, 2010.

Serreze, M. C., Barrett, A. P., Stroeve, J. C., Kindig, D. N., and Holland, M. M.: The emergence of surface-based Arctic amplification, The Cryosphere, 3, 11-19, https://doi.org/10.5194/tc-311-2009, 2009.

Stroeve, J. and Notz, D.: Insights on past and future sea-ice evolution from combining observations and models, Global Planet. Change, https://doi.org/10.1016/j.gloplacha.2015.10.011, 2015.

Stroeve, J. C., Serreze, M. C., Kay, J. E., Holland, M. M., Meier, W. N., and Barrett, A. P.: The Arctic's rapidly shrinking sea ice cover: A research synthesis, Climatic Change, 135, 119-132, https://doi.org/10.1007/s10584-011-0101-1, 2012.

Stroeve, J. C., Markus, T., Boisvert, L., Miller, J., and Barrett, A.: Changes in Arctic Melt Season and Implications for Sea Ice Loss, Geophys. Res. Lett., 110, 1005, https://doi.org/10.1002/2013GL058951, 2014.

Tilling, R. L., Ridout, A., Shepherd, A., and Wingham, D. J.: Increased arctic sea 454 ice volume after anomalously low melting in 2013, Nat. Geosci., 8, 643-646, 2015.

Tilling, R. L., Ridout, A., and Shepherd, A.: Near-real-time Arctic sea ice thickness and volume from CryoSat-2, The Cryosphere, 10, 2003-2012, https://doi.org/10.5194/tc-10-2003-2016, 2016.

Tilling, R. L., Ridout, A., and Shepherd, A.: Estimating Arctic sea ice thickness and volume using CryoSat-2 radar altimeter data, Adv. Space Res., https://doi.org/10.1016/j.asr.2017.10.051, 2017.

Tsamados, M., Feltham, D. L., Schröder, D., Flocco, D., Farrell, S. Kurtz, N., Laxon, S., and Bacon, S.: Impact of variable atmospheric and oceanic form drag on simulations of Arctic sea ice, J. Phys. Oceanogr., 44, 1329-1353, https://doi.org/10.1175/JPOD-13-0215.1, 2014.

Tsamados, M., Feltham, D., Petty, A., Schröder, D., and Flocco, D.: Processes controlling surface, bottom and lateral melt of Arctic sea ice in a state of the art sea ice model, Philos. T. R. Soc. A, 373, 2052, https://doi.org/10.1098/rsta.2014.0167, 2015.

Warren, S. G., Rigor, I. G., Untersteiner, N., Radionov, V. F., Bryazgin, N. N., Aleksandrov, Y. I., and Barry, R.: Snow depth on Arctic sea ice, J. Climate, 12, 1814-1829, 1999.

Willatt, R., Laxon, S., Giles, K., Cullen, R., Haas, C., and Helm, V.: Ku-band radar penetration into snow cover Arctic sea ice using airborne data, Ann. Glaciol., 52, 197-205, 2011. 